\title{
Article \\ Palm Temperature Differences after Static and Dynamic Load on High Bar
}

\author{
Karmen Šibanc ${ }^{1}$, Ivan Čuk ${ }^{1}$, Maja Pajek ${ }^{1}\left(\mathbb{D}\right.$ and Igor Pušnik ${ }^{2, *}$ \\ 1 Faculty of Sport, University of Ljubljana, SI-1000 Ljubljana, Slovenia; karmen.sibanc@fsp.uni-lj.si (K.Š.); \\ ivan.cuk@fsp.uni-lj.si (I.Č.); maja.pajek@fsp.uni-lj.si (M.P.) \\ 2 Faculty of Electrical Engineering, University of Ljubljana, SI-1000 Ljubljana, Slovenia \\ * Correspondence: igor.pusnik@fe.uni-lj.si
}

Citation: Šibanc, K.; Čuk, I.; Pajek, M.; Pušnik, I. Palm Temperature Differences after Static and Dynamic Load on High Bar. Sensors 2021, 21, 4497. https://doi.org/10.3390/ s21134497

Academic Editor: Nico P. Avdelidis

Received: 25 May 2021

Accepted: 28 June 2021

Published: 30 June 2021

Publisher's Note: MDPI stays neutral with regard to jurisdictional claims in published maps and institutional affiliations.

Copyright: (c) 2021 by the authors. Licensee MDPI, Basel, Switzerland. This article is an open access article distributed under the terms and conditions of the Creative Commons Attribution (CC BY) license (https:// creativecommons.org/licenses/by/ $4.0 /)$.

\begin{abstract}
Thermal imaging is used in various fields of industry and research to measure temperature and its possible differences. Since there is a lack of research and literature on palm temperatures and prevention of blisters on hands, our question was how palm temperature differs in human hands after different loads (Hang and Swing in Hang) for $30 \mathrm{~s}$ on a high bar. Thirty-eight students from the Faculty of Sport at the University of Ljubljana were measured with a high-quality thermal imaging camera. Palm temperatures were measured before the load was applied, immediately after and every $30 \mathrm{~s}$ for a period of $5 \mathrm{~min}$ after the load. Each hand was divided into nine different regions of interest (ROIs). Mean (XA), standard deviation (SD), maximum and minimum, and number of pixels were calculated. We found that there was no difference between the left and right hand. The temperature right after the load was applied decreased significantly for both loads and then increased above the level before the load was applied. After the static load, the temperature reached a constant higher level after $3 \mathrm{~min}$. After the dynamic load, the temperatures continued to increase throughout the measurement period. Further investigation is needed to determine the time period in which the hand temperature reaches the temperature before the load is applied.
\end{abstract}

Keywords: palm temperature; thermal imaging; hang; swing in hang

\section{Introduction}

The use of thermal imaging has increased in recent decades. It is now used in various fields of research (non-destructive material testing, aerial thermography, high-speed thermography, inspection of mechanical components, thermography in material testing, thermography in medicine and veterinary medicine, micro-thermography, infrared cameras for plant inspections, infrared cameras for security, sport science) and industry (aerospace industry, automotive industry, chemical industry, electronics and electrical industry, and metallurgy) [1].

Infrared thermography has been successfully used in medicine to diagnose breast cancer, diabetic neuropathy, and peripheral vascular disorders, as well as to detect problems in gynecology, kidney transplants, dermatology and chronic wound treatment [2], the heart, neonatal physiology, fever screening, and brain imaging [3,4], and dentistry [5]. In 2017, a review on the application of medical infrared thermal imaging in hands was conducted [6]. It considered 146 articles that reported on several different fields of application and presented thermal imaging as a potentially promising tool for additional non-invasive diagnostics.

In the majority of healthy subjects [7], it was observed that the temperature of the hands, feet and facial regions increased after immobilization, which can be explained by the fact that immobilization is usually followed by relaxation and blood redistribution, resulting in an increase in skin surface temperature. In addition, spontaneous oscillations have been observed in the temperature profiles of the hands and feet due to changes in the sympathetic system and blood flow. Oscillations that have a period of less than $4 \mathrm{~min}$ 
are associated with the capillaries, while those with higher periods are due to the arteriovenous anastomosis. In another study [8], cold stress was applied by placing the left hand on a cold metal surface (approximately $13^{\circ} \mathrm{C}$ ) and observing the temperature dynamics on both hands using infrared thermography. It was observed that after a steady-state period of $85 \mathrm{~s}$, the temperature on the stimulated hand decreased, while the temperature on the other hand increased over the next $90 \mathrm{~s}$. The temperature on the stimulated hand decreased and the temperature on the other hand increased. This phenomenon is attributed to the fact that the thermoregulatory mechanism responds in such a way that the core temperature remains undisturbed.

Thermal imaging is also part of research on wellbeing and in different fields of sport science that are trying to develop optimal training and results and health [9-11]. Movement of the hand consists of two basic patterns, which are termed the precision grip and the power grip [12]. In the field of sports, there are quite a few activities where the hands form a power grip and disciplines where the body is hanging (artistic gymnastics, sport climbing, fitness, Crossfit, etc.). Most of these disciplines and activities take place in a room temperature environment, but there is a lack of data on how applying palm load directly affects the palm and hand. In the power grip, extrinsic muscles play a key role in the movement by providing the major force [12].

Artistic gymnastics is the oldest organized sport. In competitions, gymnasts perform a routine consisting of various elements and the connection of such elements. Each element is defined first by the position of the gymnast according to an apparatus, secondly, by a grip or the touch of a gymnast on an apparatus, and then, by the description of the movement to the final position of an element. Routines on a high bar, rings, parallel bars, uneven bars and the pommel horse usually last between 20 and $50 \mathrm{~s}$, with an average of $30 \mathrm{~s}$ [13]. Skin injuries occur on artistic gymnastics' apparatus, where gymnasts' palms are exposed to frictional forces [14]. Frictional forces combined with pressure cause shear forces on the skin, which affect blood circulation [15,16], or more precisely, microcirculation [17], and repetitive loads and friction have effects on temperature elevation, which can cause discomfort and subsequently, skin injuries [18]. Thinner skin is more likely to blister or injure, while thicker skin requires a longer duration of stress and higher friction for injury [19]. Investigations on microcirculation in both the dorsal and palmar sides of the human fingertip have revealed anatomical and microstructural differences between the sides [17]. On the palmar side, capillary loops are arranged in rows that follow the ridges of the fingerprint, whereas the capillary loops on the dorsal side are more randomly distributed, changing orientation and direction due to the different parts of the fingernail [7].

The temperature dynamics of the surface of the human body at rest under thermoneutral conditions are determined mainly by peripheral blood flow controlled by the degree of the vasoconstriction, which is controlled almost entirely by the sympathetic nervous system in response [20]. However, blanching of the skin after the application of pressure (as happens in palms during a long swing on rings) is a well-known phenomenon, although the associated changes in skin temperature are not well investigated. The response of skin temperature to exercise has been studied [21], with a steady load leading to a constant decrease in finger temperature followed by rewarming of the hands, reflecting the dominance and balance of thermoregulatory reflexes and hemodynamics in the later phase of exercise. Graded load exercise results in a constant decrease in finger temperature due to the constant dominant vasoconstrictor response. Local cooling has been used in rehabilitation or between intense exercise sessions to reduce swelling and inflammation, and the effect of hand cooling on fatigue during high-intensity bench press has been investigated [22], but we found very few studies related to applying load or pressure to palm or handling objects at room temperature in a given time range. Bennett et al. [23] studied hand temperature after pressure for $5 \mathrm{~min}$ and discovered an initial cooling of the hand right after load application, and the application of heavy pressure resulted in a hotter hand than the application of light pressure. 
When performing simple elements on uneven bars, palm temperature differences were compared with and without the use of magnesium carbonate [24]. The palm temperature increased with the use of magnesium carbonate, while the temperature remained constant without the use of magnesium carbonate. The short-term effects of applying load on palm temperature with different shapes of gymnastic rings were compared [14], and statistical differences were found in the decrease of palm temperature after the load was applied, depending on the different shapes of rings. As one of the possible explanations for the lowering of palm temperature, the researchers point to the movement in the hanging position on rings, since the palm as the contact surface is high above the level of the heart at the reachable height, which causes a disturbance in blood flow to the hand. At rest and under thermoneutral conditions, the temperature dynamics of the human body surface is mainly determined by peripheral blood flow [25].

In our research, we were interested in the differences between the static and dynamic load applications, where the friction force is different.

In recent research [14], the thermograms showed a different temperature distribution in the area of the hands, so, we focused on more regions of interest (ROI) according to the load. Healthy skin temperatures are supposed to be regarded as symmetrically distributed [26], however, according to the demonstrated asymmetries in gymnastics [27,28] and a study that showed left-right asymmetry in hand temperature after cold stress [29], we also checked whether there are asymmetries between the left and right hands after the load was applied. Since temperature recovery period is not well investigated, according to Gulyaev et al.'s research [7], where temperatures returned to their level before occlusion after 2-3 min, the selected period for our measurement was $5 \mathrm{~min}$, even though Bennett et al.'s study [23] showed some different patterns after a $10 \mathrm{~min}$ recovery period.

From the above studies $[3,4,7,8,14]$, it was found that in grasping during the execution after the loads and their amplitude, the differences in the temperature of the skin of the palm were very different, and in long-term hanging, it was found that the temperature of the palm decreased. Therefore, we wanted to find out what happens in the case of static (Hang) and dynamic loads (Swing in Hang, denoted as "Swing" in the following text) when hanging on the high bar for a duration of $30 \mathrm{~s}$, which is the average duration of the exercise performance. When hanging, the entire body is under contact with an apparatus.

\section{Materials and Methods}

The subjects were 38 ( 27 women and 11 men) healthy students from the Faculty of Sport, University of Ljubljana. The average age was 22.1 years $( \pm 2.9)$, height $1.73 \mathrm{~m}( \pm 0.10)$, and body weight $72.2 \mathrm{~kg}( \pm 12.5)$. All included subjects gave written informed consent and the Declaration of Helsinki was followed. Ethical approval was obtained from the Ethical Commission of the University of Ljubljana's Faculty of Sport (12_2018).

The authors developed the measurement protocol according to our hypotheses:

Hypothesis 1. Palm temperature decreases after application of the static load in hang.

Hypothesis 2. Palm temperature increases after application of the dynamic load in swing while in hang.

Hand temperatures of the subjects were measured before the load was applied, immediately after the load, and then for $5 \mathrm{~min}$ at $30 \mathrm{~s}$ intervals (12 thermograms per subject per load). The thermography setting is shown in Figure 1: the subject is in a seated position, hands resting on the table with fingers spaced at approximately the level of the heart and on an additional insulating surface to prevent heat loss into the table. Subjects were required to perform two tasks on the high bar (steel, $\varnothing=28 \mathrm{~mm}$ ); $30 \mathrm{~s}$ of still hanging (Figure 2a) and $30 \mathrm{~s}$ of swinging while hanging (Figure $2 \mathrm{~b}$ ) with a fixed swing range (approximately 30 degrees from the vertical position). Subjects were evenly and randomly assigned the task that they performed first. The handgrip for both tasks was a cylindrical power grip. The measurements took place in the gymnastics hall of the Faculty of Sport, University of 
Ljubljana. The temperature in the hall was $23{ }^{\circ} \mathrm{C}$ and the relative humidity was $40 \%$. All subjects were in the hall for acclimatization 15 min before the start of the first measurement. They were asked not to drink alcohol or smoke for $24 \mathrm{~h}$, not to consume caffeine for $12 \mathrm{~h}$, and not to use creams or lotions on their hands for $12 \mathrm{~h}$ before the measurements [30]. The skin on their hands was not visibly damaged.

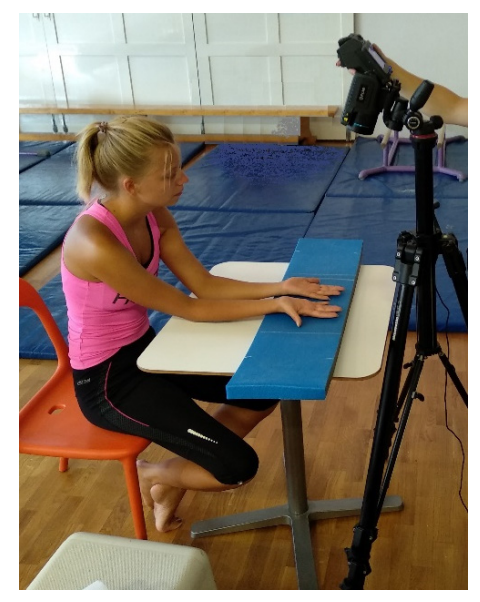

Figure 1. Camera setting while taking thermal images.

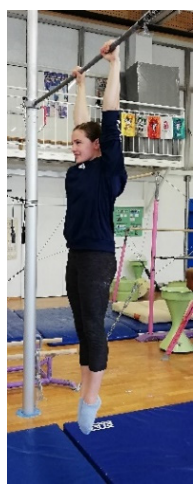

(a)

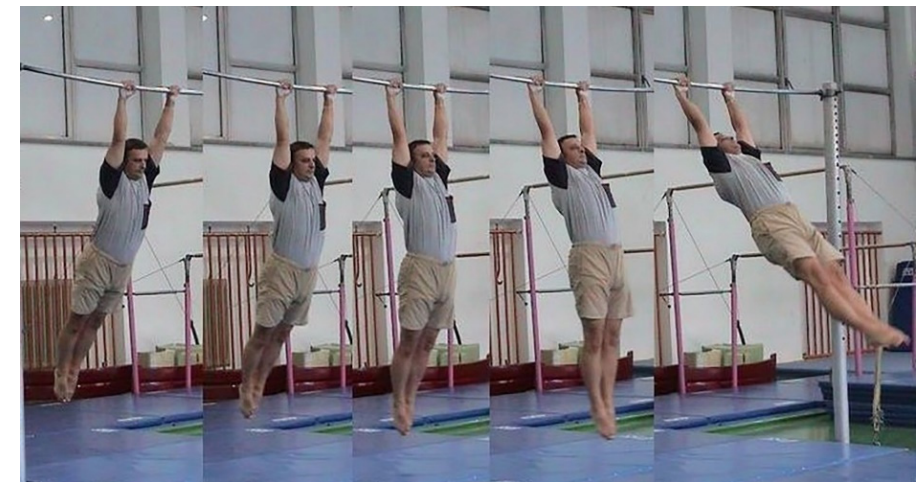

(b)

Figure 2. (a) Hang and (b) Swing.

A high-quality thermal imaging camera (FLIR T650sc FLIR Systems, Wilsonville, OR, USA) was used in the study. The detector type was an uncooled microbolometer with the FPA, operating in the spectral range from $7.5 \mu \mathrm{m}$ to $14 \mu \mathrm{m}$, noise equivalent temperature difference NETD $<30 \mathrm{mK}$, and a specified accuracy of $\pm 1 \%$ of reading or $1{ }^{\circ} \mathrm{C}$ in the temperature range from $5^{\circ} \mathrm{C}$ to $120^{\circ} \mathrm{C}$, at ambient temperatures $10^{\circ} \mathrm{C}$ to $35^{\circ} \mathrm{C}$. The camera was calibrated prior to the research measurements in the LMK-Laboratory of Metrology and Quality at the Faculty of Electrical Engineering, University of Ljubljana (LMK is the holder of the Slovenian national standard for thermodynamic temperature. As a national laboratory for temperature and relative humidity and as an accredited calibration laboratory, it has CMCs-calibration measurement capabilities that are among the best in Europe and worldwide in the respective fields of measurement, which confirms its accuracy. The camera has a wide-angle $45^{\circ}$ lens $(\mathrm{f}=13.1 \mathrm{~mm})$ with the field of view $(\mathrm{FOV})$ of $45^{\circ} \times 34^{\circ} \mathrm{mm}$, spatial resolution of $1.23 \mathrm{mrad}(\mathrm{IFOV})$, continuous zoom $(8 \times)$ and a minimum focus distance of $15 \mathrm{~cm}$. The emissivity value can be set in steps of 0.01 from 0.10 to 1.00. Measurements were corrected for the reflected temperature, optics transmission, atmospheric transmission and external optics. Image analysis in the associated software environment (ResearchIR Max by (FLIR Systems, Wilsonville, OR, USA) enabled the analysis of different ROIs, e.g., spots, areas, automatic hot/cold point detection, difference 
of temperature, isotherms, line profiles, alarms, temporal temperature dependence, etc. The resolution of the camera is $640 \times 480$ pixels, which amounts to 307,200-pixel temperatures in a single thermogram. This high resolution is important for a comprehensive analysis of the selected ROIs [31].

We divided each hand into nine ROIs (polygons), as shown in Figure 3, using the ResearchIR application: Palm, Thumb, Index Finger Proximal Phalanx, Index Finger Distal Phalanges, Middle Finger Proximal Phalanx, Middle Finger Distal Phalanges, Ring Finger Proximal Phalanx, Ring Finger Distal Phalanges and Little Finger. Table 1 contains the ROIs shown in Figure 3 and the abbreviations used in the following text for each ROI. A very important point in the analysis of thermal images is the drawing of ROIs, taking into account that the boundary of the ROI must be at least 7 pixels away from the edge of the observed surface to avoid the influence of the size-of source effect [32].

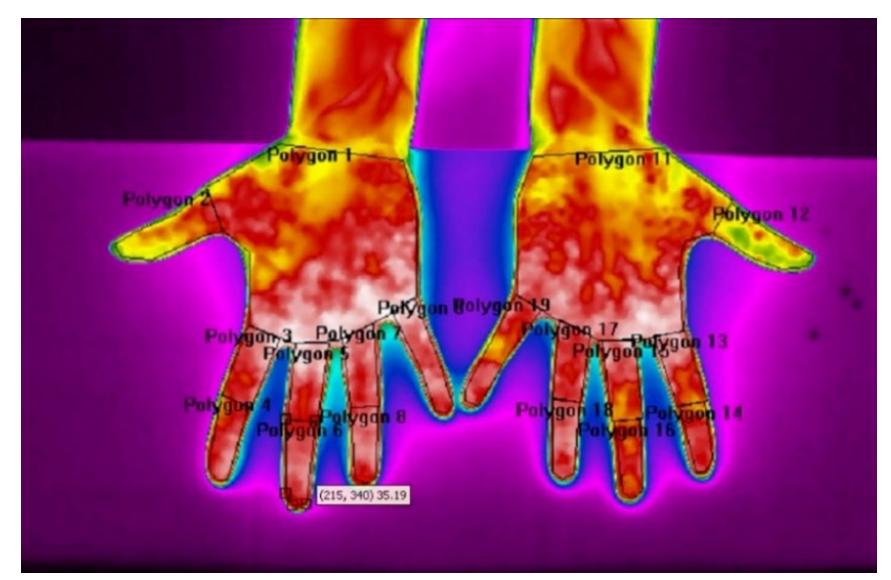

Figure 3. Thermal image and ROI on hands.

Table 1. ROIs on each hands.

\begin{tabular}{cccc}
\hline Hand & Polygon & ROI & Abbreviation \\
\hline \multirow{4}{*}{ Right Hand } & Polygon 1 & Palm & P-R \\
& Polygon 2 & Thumb & T-R \\
& Polygon 3 & Index Finger Proximal Phalanx & IPP-R \\
& Polygon 4 & Index Finger Distal Phalanges & IDP-R \\
& Polygon 5 & Middle Finger Proximal Phalanx & MPP-R \\
& Polygon 6 & Middle Finger Distal Phalanges & MDP-R \\
& Polygon 7 & Ring Finger Proximal Phalanx & RPP-R \\
& Polygon 8 & Ring Finger Distal Phalanges & RDP-R \\
& Polygon 9 & Little Finger & LF-R \\
& Polygon 11 & Palm & P-L \\
& Polygon 12 & Thumb & IPP-L \\
& Polygon 13 & Index Finger Proximal Phalanx & IDP-L \\
& Polygon 14 & Index Finger Distal Phalanges & MPP-L \\
& Polygon 15 & Middle Finger Proximal Phalanx & MDP-L \\
& Polygon 16 & Middle Finger Distal Phalanges & RPP-L \\
& Polygon 17 & Ring Finger Proximal Phalanx & RDP-L \\
& Polygon 18 & Ring Finger Distal Phalanges & LF-L \\
\hline
\end{tabular}

Data from ResearchIR were exported to Excel for Windows 10 (Microsoft Corporation, Redmond, WA, United States) for each ROI including mean (XA), standard deviation (SD), maximum and minimum, and number of pixels. In Excel, we calculated two new variables. The first one represents the sum of temperature differences of the section before the task until the end of the 5 th minute using the formula $\Sigma\left(T_{n}-T_{n}+1\right)$, where $n$ represents the time series. The second variable was calculated as temperature differences from the 
first to the last measurement using the formula $T_{1}-T_{n}+1$, where $n$ represents the time series. Statistical analyses were performed in SPSS 25.0 (IBM corp.). The values of the Kolmogorov-Smirnov test, means (XA), standard deviations (SD), standard errors (SE) were calculated for each sector variable and the pairwise Student's t-test was used (to compare the temperature difference between Hang and Swing, between the left and right sectors, and between the time series in each task). The figures and graphs were created using Excel software.

\section{Results}

According to the Kolmogorov-Smirnov test, variables were not normally distributed.

No significant difference was observed between men and women, which was also found in other studies [33]. Since there was no significant difference between the left and the right hand, the results are presented for the left hand.

For all ROIs, there was a significant difference $(p<0.05)$ between the temperatures in Hang and Swing. The sum temperature difference in $330 \mathrm{~s}$ (the total measurement time including load in the first $30 \mathrm{~s}$ ) for the Left Hand from the ROI is shown in Table 2.

Table 2. Sum temperature difference for Hang and Swing in $330 \mathrm{~s}$ for Left Hand by ROI.

\begin{tabular}{|c|c|c|c|c|c|}
\hline Variable & $\mathrm{XA} /{ }^{\circ} \mathrm{C}$ & $\mathrm{XA}_{\mathrm{H}}-\mathrm{XA}_{\mathrm{S}} /{ }^{\circ} \mathrm{C}$ & $\mathrm{SD} /{ }^{\circ} \mathrm{C}$ & $\mathrm{SE} /{ }^{\circ} \mathrm{C}$ & $p(t$-Test) \\
\hline Hang $\mathrm{P}^{\mathrm{a}}-\mathrm{L}$ & 0.46 & \multirow{2}{*}{0.63} & 0.70 & 0.11 & \multirow[b]{2}{*}{0.003} \\
\hline Swing $\mathrm{P}^{\mathrm{a}}-\mathrm{L}$ & 1.09 & & 1.04 & 0.17 & \\
\hline Hang $\mathrm{T}^{\mathrm{b}}-\mathrm{L}$ & 0.19 & \multirow{2}{*}{0.83} & 0.92 & 0.15 & \multirow{2}{*}{0.004} \\
\hline Swing $\mathrm{T}^{\mathrm{b}}-\mathrm{L}$ & 1.02 & & 1.43 & 0.23 & \\
\hline Hang IPP $\mathrm{c}_{-} \mathrm{L}$ & 0.66 & \multirow[b]{2}{*}{1.16} & 1.09 & 0.18 & \multirow[b]{2}{*}{0.000} \\
\hline Swing IPP ${ }^{\mathrm{c}}-\mathrm{L}$ & 1.83 & & 1.55 & 0.25 & \\
\hline Hang IDP ${ }^{\mathrm{d}_{-}-\mathrm{L}}$ & 0.33 & \multirow{2}{*}{1.42} & 1.21 & 0.20 & \multirow{2}{*}{0.000} \\
\hline Swing IDP ${ }^{\mathrm{d}_{-}}$L & 1.75 & & 1.89 & 0.31 & \\
\hline Hang MPP ${ }^{\mathrm{e}}-\mathrm{L}$ & 0.77 & \multirow[b]{2}{*}{1.08} & 0.93 & 0.15 & \multirow[b]{2}{*}{0.001} \\
\hline Swing MPP $\mathrm{e}_{-\mathrm{L}}$ & 1.85 & & 1.54 & 0.25 & \\
\hline Hang MDP ${ }^{\mathrm{f}}-\mathrm{L}$ & 0.49 & \multirow{2}{*}{1.23} & 1.13 & 0.18 & \multirow[b]{2}{*}{0.001} \\
\hline Swing MDP ${ }^{\mathrm{f}}-\mathrm{L}$ & 1.71 & & 1.86 & 0.30 & \\
\hline Hang RPP g-L & 0.89 & \multirow{2}{*}{1.06} & 1.03 & 0.17 & \multirow{2}{*}{0.005} \\
\hline Swing RPP g-L & 1.95 & & 1.76 & 0.28 & \\
\hline Hang RDP ${ }^{\mathrm{h}}-\mathrm{L}$ & 0.52 & \multirow{2}{*}{1.63} & 1.32 & 0.21 & \multirow[b]{2}{*}{0.001} \\
\hline Swing RDP ${ }^{\mathrm{h}}-\mathrm{L}$ & 2.15 & & 2.27 & 0.37 & \\
\hline Hang LF ${ }^{\mathrm{i}}$-L & 0.57 & \multirow{2}{*}{1.84} & 1.13 & 0.18 & \multirow[b]{2}{*}{0.000} \\
\hline Swing LF ${ }^{\mathrm{i}}-\mathrm{L}$ & 2.41 & & 2.27 & 0.37 & \\
\hline
\end{tabular}

Note: ${ }^{\text {a }} \mathrm{P}=$ Palm; ${ }^{\mathrm{b}} \mathrm{T}=\mathrm{Thumb}^{\mathrm{c}} \mathrm{IPP}=$ Index Finger Proximal Phalanx; ${ }^{\mathrm{d}}$ IDP $=$ Index Finger Distal Phalanges ${ }^{\mathrm{e}}$ MPP $=$ Medial Finger Proximal Phalanx; ${ }^{\mathrm{f}}$ MDP $=$ Medial Finger Distal Phalanges; ${ }^{\mathrm{g}} \mathrm{RPP}=$ Ring Finger Proximal Phalanx; ${ }^{\text {h }}$ RDP = Ring Finger Distal Phalanges $;{ }^{i}$ LF $=$ Little Finger.

All values were higher for Swing than for Hang, with the minimum difference always being Palm and the maximum difference always being Little Finger. We can also see that there was a difference between the proximal phalanx and distal phalanges for the Index, Middle and Ring Finger. The average of mean temperatures (XA) in Swing was higher than the average of mean temperatures in Hang, ranging from the minimum $0.63^{\circ} \mathrm{C}$ (for Palm) to the maximum $1.83^{\circ} \mathrm{C}$ (for Little Finger), the minimum SD was $0.34^{\circ} \mathrm{C}$ for Palm and the maximum was $1.14{ }^{\circ} \mathrm{C}$ for Little Finger, the minimum SE was $0.06{ }^{\circ} \mathrm{C}$ for Palm and the maximum was $0.18^{\circ} \mathrm{C}$ for Little Finger.

Table 3 shows the significant difference in temperature by time and region before and after applying load, which was applied for each $30 \mathrm{~s}$ during a period of $5 \mathrm{~min}$, where "+" means a significant difference in temperature by $t$-test $(p<0.05)$. In Hang, the difference in temperature every $30 \mathrm{~s}$ after the application of load was significant for all ROIs up to $150 \mathrm{~s}$, for Palm up to $180 \mathrm{~s}$, and for all Proximal Phalanx up to $210 \mathrm{~s}$.

According to Swing, the temperature difference was significant for all ROIs until $180 \mathrm{~s}$ after applying the load, reached a plateau at $210 \mathrm{~s}$ where the difference was not significant, 
the difference was again significant for all ROIs after $240 \mathrm{~s}$ and then again for Proximal Phalanx and Palm in the last minute of the measurement.

Table 3. Difference in temperature by time and region (where + means significant difference by $t$-test $(p<0.05)$ ) for Hang and Swing for Left Hand.

\begin{tabular}{|c|c|c|c|c|c|c|c|c|c|c|c|c|}
\hline Variable & $-30 / \mathrm{s}$ & $0 / \mathrm{s}$ & $30 / \mathrm{s}$ & $60 / \mathrm{s}$ & $90 / \mathrm{s}$ & $120 / \mathrm{s}$ & $150 / \mathrm{s}$ & $180 / \mathrm{s}$ & $210 / s$ & $240 / s$ & $270 / s$ & $300 / \mathrm{s}$ \\
\hline Hang $\mathrm{P}^{\mathrm{a}}-\mathrm{L}$ & & + & + & + & + & + & + & + & & & & \\
\hline Swing $\mathrm{P}^{\mathrm{a}}-\mathrm{L}$ & & + & + & + & + & + & + & & & & & \\
\hline Hang $\mathrm{T}^{\mathrm{b}}-\mathrm{L}$ & & + & + & + & + & + & + & + & + & & & \\
\hline Swing $\mathrm{T}^{\mathrm{b}}-\mathrm{L}$ & & + & + & + & + & + & + & & & & & \\
\hline Hang IPP ${ }^{\mathrm{c}}-\mathrm{L}$ & & + & + & + & + & + & + & + & + & & & \\
\hline Swing IPP ${ }^{\mathrm{c}}-\mathrm{L}$ & & + & + & + & + & + & + & & & & & \\
\hline Hang IDP ${ }^{d}-L$ & & + & + & + & + & + & + & + & + & & & \\
\hline Swing IDP ${ }^{d_{-}}$L & & + & + & + & + & + & + & & & & & \\
\hline Hang MPP ${ }^{\mathrm{e}}-\mathrm{L}$ & & + & + & + & + & + & + & & & & & \\
\hline Swing MPP ${ }^{\mathrm{e}}-\mathrm{L}$ & & + & + & + & + & + & + & + & & + & & + \\
\hline Hang MDP ${ }^{\mathrm{f}}-\mathrm{L}$ & & + & + & + & + & + & + & + & & + & & \\
\hline Swing MDP ${ }^{\mathrm{f}}-\mathrm{L}$ & & + & + & + & + & + & + & + & & + & & + \\
\hline Hang RPP g-L & & + & + & + & + & + & + & + & & + & & \\
\hline Swing RPP g-L & & + & + & + & + & + & + & + & & + & & + \\
\hline Hang RDP ${ }^{\mathrm{h}}-\mathrm{L}$ & & + & + & + & + & + & + & + & & + & & \\
\hline Swing RDP ${ }^{h}-L$ & & + & + & + & + & + & + & + & & + & + & \\
\hline Hang LF ${ }^{\mathrm{i}}$-L & & + & + & + & + & + & + & + & & + & & \\
\hline Swing $\mathrm{LF}^{\mathrm{i}}-\mathrm{L}$ & & + & + & + & + & + & + & + & & + & & \\
\hline
\end{tabular}

Note: ${ }^{\mathrm{a}} \mathrm{P}=$ Palm; ${ }^{\mathrm{b}} \mathrm{T}=\mathrm{Thumb}^{\mathrm{c}} \mathrm{IPP}=$ Index Finger Proximal Phalanx; ${ }^{\mathrm{d}} \mathrm{IDP}=$ Index Finger Distal Phalanges; ${ }^{\mathrm{e}}$ MPP $=$ Medial Finger Proximal Phalanx; ${ }^{\mathrm{f}} \mathrm{MDP}=$ Medial Finger Distal Phalanges; ${ }^{\mathrm{g}} \mathrm{RPP}=$ Ring Finger Proximal Phalanx; ${ }^{\mathrm{h}} \mathrm{RDP}=$ Ring Finger Distal Phalanges; ${ }^{\mathrm{i}} \mathrm{LF}=$ Little Finger.

The mean temperature differences with respect to the time course are shown in Figures 4 and 5 .

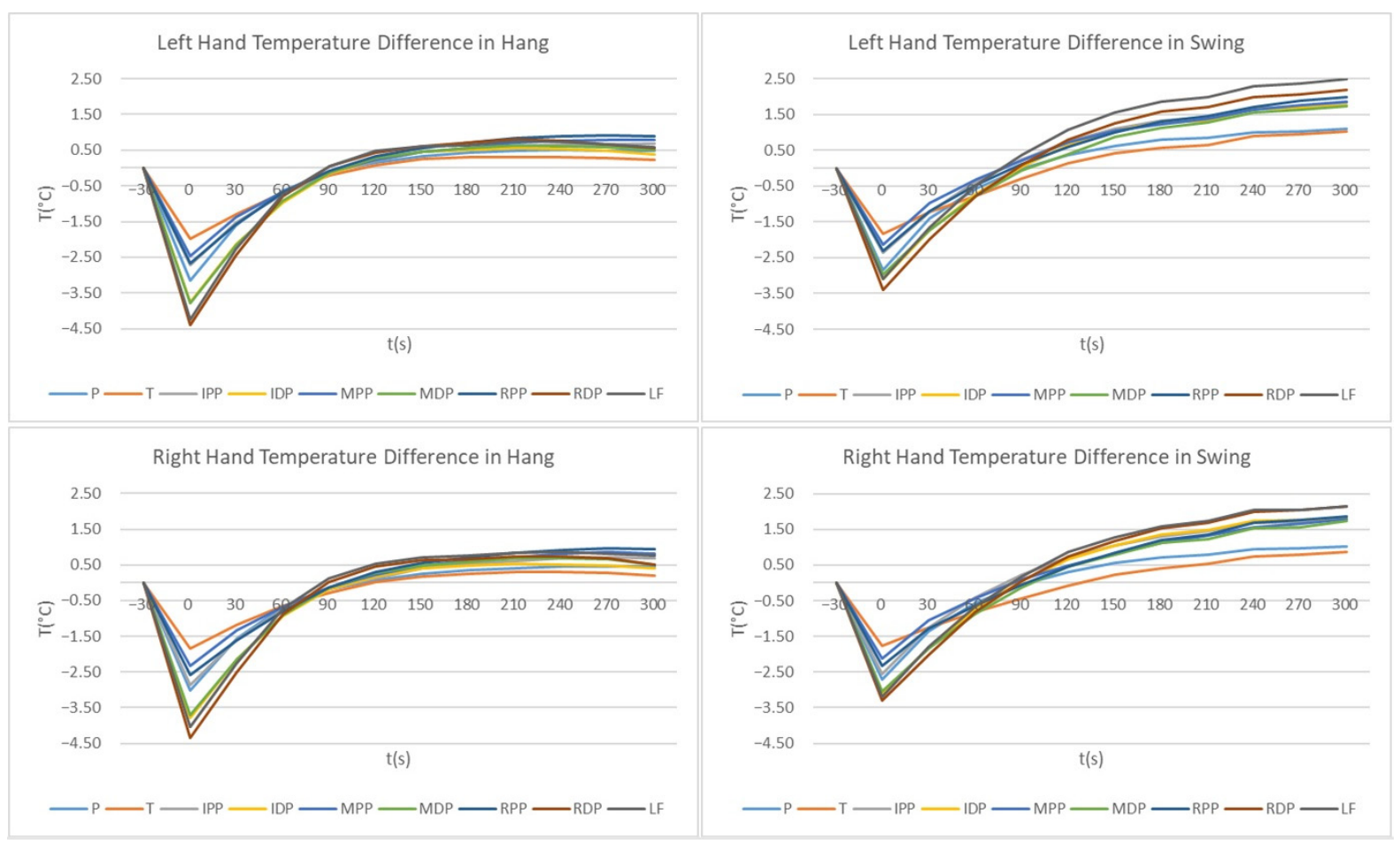

Figure 4. Right- and Left-Hand temperature difference in Hang and Swing. Both charts on the left side of the figure present temperature differences for Hang and the charts on the right side of the figure present temperature differences for Swing. The upper two charts present the left hand and the lower two charts present the right hand. 


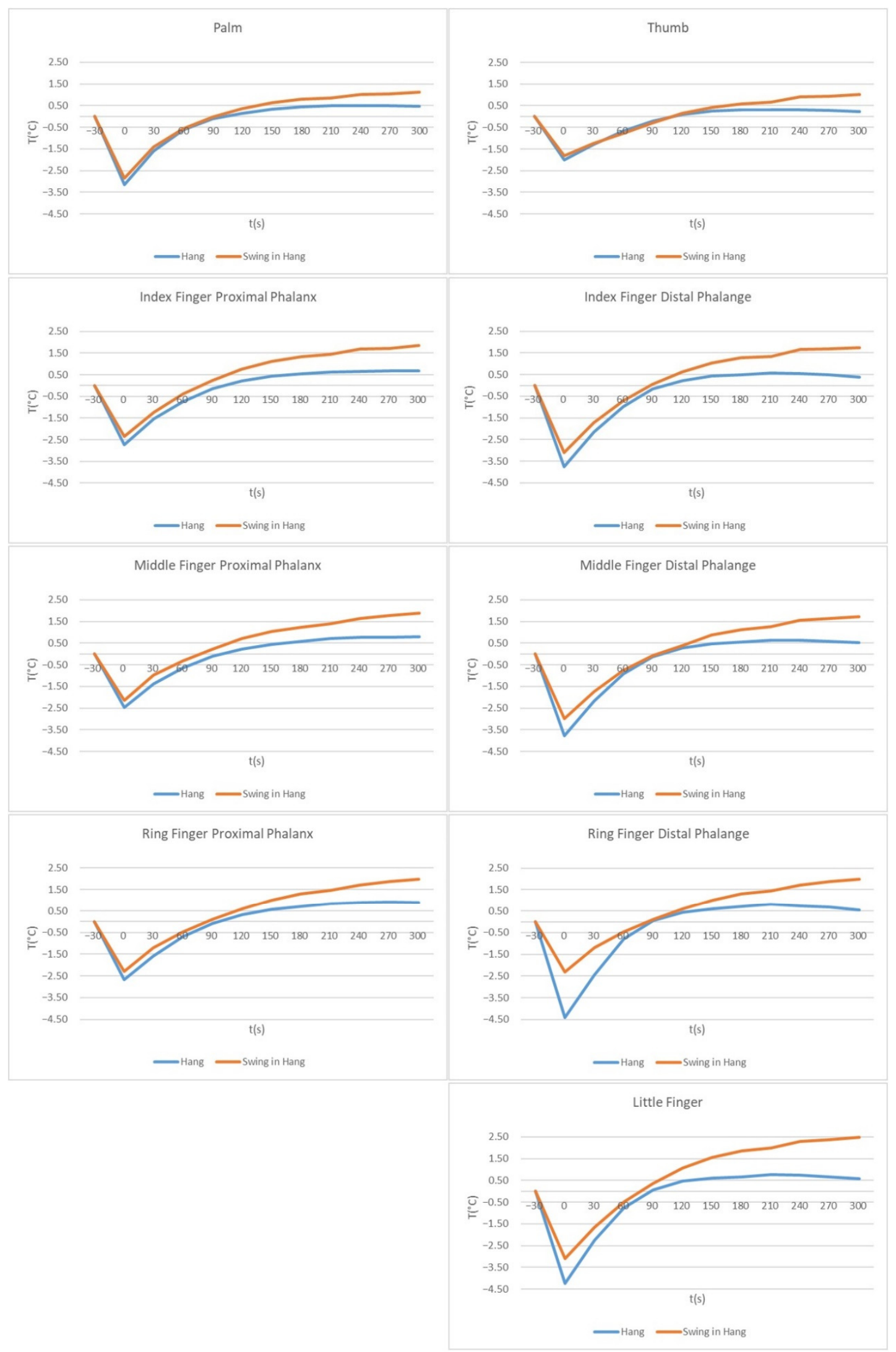

Figure 5. Left-Hand temperature difference in Hang and in Swing for different ROIs. Charts on the left side of the figure present temperature values for Palm and all three Proximal Phalanx; charts on the right present values for the Thumb, all three Distal Phalanges and Little Finger. The values for Index, Middle and Ring Finger Phalanx/Phalanges are in line for each finger. 
The temperature differences between Hang and Swing are shown in Table 4. Immediately after the application of the load, a significant difference was observed for the Palm, Little Finger and all fingers of the distal phalanges. For the Index Finger Proximal Phalanx the temperature differences were significant from $60 \mathrm{~s}$ to the end of the $5 \mathrm{~min}$ period. Up to $210 \mathrm{~s}$, the temperature distribution was similar for each ROI and the difference was not significant. For all ROIs, from 240 s onwards, there was a significant difference, as the temperatures of all ROIs were higher after Swing than after Hang.

Table 4. Differences between the Hang and Swing time series (where + indicates significant difference by $t$-test $(p<0.05)$ ) for left hand.

\begin{tabular}{|c|c|c|c|c|c|c|c|c|c|c|c|c|}
\hline Variables & $-30 / \mathrm{s}$ & $0 / \mathrm{s}$ & $30 / \mathrm{s}$ & $60 / \mathrm{s}$ & $90 / \mathrm{s}$ & $120 / \mathrm{s}$ & $150 / \mathrm{s}$ & $180 / \mathrm{s}$ & $210 / \mathrm{s}$ & $240 / \mathrm{s}$ & $270 / \mathrm{s}$ & $300 / \mathrm{s}$ \\
\hline $\mathrm{P}^{\mathrm{a}}-\mathrm{L}$ & & + & & & & & & + & & + & + & + \\
\hline $\mathrm{T}^{\mathrm{b}}-\mathrm{L}$ & & & & & & & & & & + & + & + \\
\hline IPP ${ }^{c_{-}}-$ & & & & + & + & + & + & + & + & + & + & + \\
\hline IDP $^{\mathrm{d}_{-L}}$ & & + & & & & & + & + & + & + & + & + \\
\hline$M P P^{e}-L$ & & & + & + & & & + & + & + & + & + & + \\
\hline $\mathrm{MDP}^{\mathrm{f}}-\mathrm{L}$ & & + & & & & & & & & + & + & + \\
\hline RPP g-L & & & + & & & & & + & & + & + & + \\
\hline $\mathrm{RDP}^{\mathrm{h}}-\mathrm{L}$ & & + & & & & & & + & + & + & + & + \\
\hline $\mathrm{LF}^{\mathrm{i}}-\mathrm{L}$ & & + & + & & & + & + & + & + & + & + & + \\
\hline
\end{tabular}

Note: ${ }^{\mathrm{a}} \mathrm{P}=$ Palm; ${ }^{\mathrm{b}} \mathrm{T}=$ Thumb; ${ }^{\mathrm{c}} \mathrm{IPP}=$ Index Finger Proximal Phalanx; ${ }^{\mathrm{d}} \mathrm{IDP}=$ Index Finger Distal Phalanges; ${ }^{\mathrm{e}}$ MPP $=\mathrm{Medial}$ Finger Proximal Phalanx; ${ }^{\mathrm{f}} \mathrm{MDP}=$ Medial Finger Distal Phalanges; ${ }^{\mathrm{g}} \mathrm{RPP}=$ Ring Finger Proximal Phalanx; ${ }^{\mathrm{h}} \mathrm{RDP}=\mathrm{Ring}$ Finger Distal Phalanges; ${ }^{\mathrm{i}} \mathrm{LF}=$ Little Finger.

Figure 4 shows the mean temperature differences for Hang and Swing for the left and right hand for all the measured ROIs in the hands.

There was hardly any difference between the left and the right hand for both loads, while a significant difference between the loads can be seen in Figure 5. For both loads, for ROIs where the temperature decrease was larger, the temperature increase was larger according to the temperature before the load. The temperature decrease for Hang was larger than for Swing (after Hang, the temperature decrease was $1.99-4.39{ }^{\circ} \mathrm{C}$ and after swing, it was $1.83-3.40^{\circ} \mathrm{C}$ ). After both loads, Thumb had the smallest temperature difference. After Hang, the temperature values of the ROIs decreased immediately after the load by $-1.99{ }^{\circ} \mathrm{C}$ (Thumb) to $-4.39{ }^{\circ} \mathrm{C}$ (Ring Finger Distal Phalanges) corresponding to the temperatures before the load. Three hundred seconds after Hang, the temperature of the ROIs increased to larger values than before applying the load for $0.22{ }^{\circ} \mathrm{C}$ (Thumb) to $0.90{ }^{\circ} \mathrm{C}$ (Ring Finger Proximal Phalanx). After Swing, the temperature of the ROIs decreased to less than after Hang, from $-1.83{ }^{\circ} \mathrm{C}$ (Thumb) to $-3.40{ }^{\circ} \mathrm{C}$ (Ring Finger Distal Phalanges), corresponding to pre-load temperatures. Three hundred seconds after the Swing, temperatures increased by $1.02{ }^{\circ} \mathrm{C}$ (Thumb) to $2.49{ }^{\circ} \mathrm{C}$ (Little Finger), corresponding to pre-load temperatures.

In Hang, the rise in temperature above the initial value (before the load was applied) was very similar for all ROIs, appearing between 90 and $120 \mathrm{~s}$ after the load, while after Swing, the temperatures of the ROIs reached their initial values between $75 \mathrm{~s}$ and $110 \mathrm{~s}$ after the load. As shown in Table 3, the temperature changes after Hang reached a plateau about $150 \mathrm{~s}$ to $180 \mathrm{~s}$ after the load, which can also be seen clearly from the curves in Figures 4 and 5. After the Swing (according to Figures 4 and 5 and Table 3), the plateau can be seen at $210 \mathrm{~s}$, but the temperatures still increased significantly after $240 \mathrm{~s}$.

Figure 5 shows the temperature difference between Hang and Swing for each ROI separately. The smallest difference between Hang and Swing was for the Palm. The Thumb in this study showed the smallest temperature difference in general-in addition to small temperature differences between loads (up to $120 \mathrm{~s}$ after load application), it also showed the smallest temperature decrease after load. A difference was observed between the proximal phalanxes and distal phalanges. For all distal phalanges and the Little Finger, the temperature differences between Hang and Swing were larger than for the proximal phalanxes (and Palm and Thumb), as mentioned above. The greater difference 
between Hang and Swing was in the Ring's Finger Distal Phalange immediately after load application, and in the Little Finger $90 \mathrm{~s}$ after load application. In the index and middle fingers, the temperature decrease was much larger in distal phalanges. In the ring finger, the temperature difference between the phalanx and phalange after Swing was not very large, while in Hang, the temperature decrease after load application was larger in the Distal Phalange than in the Ring Finger's Proximal Phalanx.

\section{Discussion}

Despite the demonstrated asymmetries in artistic gymnastics $[27,28]$, the temperature of the hands in a static position is symmetrical in healthy subjects [34], and the temperature difference and distribution between the left and the right hand in our study before and after the load application appeared to be symmetrical. The loads included in this study, Hang and Swing, are symmetrical positions/movements (compared to the aforementioned studies on gymnastics) and did not include movements such as rotations or twists around the longitudinal or transverse axis, hanging on one hand, etc. This means that possible body asymmetries had no influence on the temperature differences of the hands after load application.

The temperature difference was higher in all ROIs under dynamic load than under static load, the $t$-test proves a significant difference between the loads for the whole period of our measurement, with the biggest difference being on the distal phalanges of the ring and index finger, as well as the Little Finger. This could be related to a previous study [7], where the authors showed that the response to the hands starts at the fingertips and progresses in a wave-like manner to the upper parts of the hand. In their study, they examined hand temperature after immobilization, which was similar to our study but without the load. Adding the load indicates greater forces on the skin, considering gravity and grip during the Swing, the distal phalanges bear most of the body weight in the second part of the swing where the whole body (except the palms) was in front of the bar. This is also evident in the comparison of temperature differences after the Hang and the Swing (Table 4). Significant differences immediately after load application were found on the Palm, Little Finger and distal phalanges of all three fingers. Thirty seconds after load application the significant difference was at the proximal phalanxes of the middle and ring fingers and the Little Finger, showing the different responses of the palms to the temperature distribution and thermoregulation mechanism. Significant temperature differences between Hang and Swing were observed in all ROIs $240 \mathrm{~s}$ after loading, but we cannot forget that significant temperature differences were prominent for the Index Finger Proximal Phalanx and Little finger. As personally experienced by the authors, the index finger seemed to be the most loaded during Hang and Swing. Further research on this topic is needed. Research on rings [14] found that the reasons for lower palm skin temperature (immediately after load application) may be related to the position of the hands above the heart and the shape of the rings. When the fist is formed to grip, it forms an outward bowed shape, which would mean that the Index and the Little Finger are subjected to higher pressure and gripping force when hanging on a bar; this is also due to gravitational force.

As shown in Table 3, the temperature differences were significant every $30 \mathrm{~s}$. For a longer period, the differences were significant for the Palm and proximal phalanxes; the temperatures of the Thumb and distal parts of the Palm reached a certain level where the temperature was higher than before the load application and no longer changed significantly. This is similar for both loads, but happened earlier in Hang than in Swing. In Hang, the temperatures reached a new constant level after 3 or $4 \mathrm{~min}$, which we did not observe after Swing.

The Thumb had the smallest temperature difference. According to the cylindrical power grip, where the Thumb is oriented differently compared to digits $2-5$, it is a key anatomical feature of the hand that allows for this opposite orientation and a much stronger grip [35]. The Thumb was the only finger that was under the bar and was not affected 
by gravity like the other fingers. Skin contact with the bar and the thumb was mostly on the inner side of the thumb and the angle of our settings was not ideal for sensing the thumb's temperature.

As shown in Figures 4 and 5, for all measurements, we see the temperature decrease immediately after the load was applied. After the static load, the temperature decrease was greater than after the dynamic load, but then, the temperatures reached a higher constant level (corresponding to the pre-load temperatures) after about $180 \mathrm{~s}$, remained at this level until 240 or $270 \mathrm{~s}$, and then the temperatures decreased again slightly (except for the proximal parts of the index and middle fingers). Immediately after dynamic load application, temperatures decreased (lower than after static load), followed by a mostly similar increase in temperature up to $90 \mathrm{~s}$. The index and middle finger temperatures were similar. Subsequently, temperatures of all ROIs reached higher values than after the static load (see Figure 5), and temperatures continued to increase until $300 \mathrm{~s}$ after load application. Longer measurements would be necessary to determine the time at which temperatures reached pre-load application values. Repetitions of exercise routines are necessary in gymnastics training [13], and constant loading of the palms and a constant increase in palm temperature could lead to blisters on the palms. Blisters are the most common injury of the palm. However, they are not counted among the typical injuries because they are not treated in medical centers [36,37]. With proper rest during training and competition, palm injuries could be reduced.

One of the possible explanations for a decrease in palm temperature could be the change in the blood flow in the palm while executing elements in the hanging position [14]. Measurement of skin blood flow is usually accomplished by laser Doppler flowmetry or venous occlusion plethysmography This method offers the advantages of high temporal resolution (measurements can be taken continuously) and specificity to the cutaneous microcirculation. It has already been found that when the fist was clenched the blood flow had high resistance and after releasing (after $3 \mathrm{~min}$ ) the blood flow had low resistance. This response is mainly the consequence of ischemia of the whole palm, which occurs with clenching of the fist [38]. To evaluate this hypothesis and better investigation we suggest that future studies should include measurements of mean volume flow through the radial artery.

\section{Conclusions}

In artistic gymnastics, palm loads are part of training and competition on all apparatus. Especially on the bars (high bar, parallel bars and uneven bars) and on the rings, the hanging position is performed, where the risk of palm injury due to palm load application is high. With this study, we can conclude that in Hang (static load) and Swing (dynamic load), the temperature distribution for the left and right hand is symmetrical. In both static and dynamic load application, temperatures decreased significantly by about $3{ }^{\circ} \mathrm{C}\left( \pm 1.2^{\circ} \mathrm{C}\right)$ immediately after the load application and then began to increase, reaching higher values than before the load was applied. Consequently, our first hypothesis was accepted and the second hypothesis was rejected. After the static load was applied, the temperature decrease was significantly larger than after the dynamic load (by $0.5^{\circ} \mathrm{C}$ on average) and after about $210 \mathrm{~s}$, when the highest temperature values were reached (between 0.32 and $0.90^{\circ} \mathrm{C}$ higher than before the load was applied), it slowly started to decrease. After application of the dynamic load, the temperature decrease was lower than after application of the static load, but then continued to increase over the entire period of measurement, and after $5 \mathrm{~min}$ it was $1.0-2.5^{\circ} \mathrm{C}$ higher than before the load was applied.

\section{Strength and Limitations}

Because of the large database, Tables with all values were not included.

With this study, we started to question the efficiency of time of rest for possible skin injury prevention. According to our results, further investigations should be conducted to obtain more information about the time for skin temperature to reach its value before the 
load. Thermography, as a non-invasive and non-radiating analysis tool has not been used to answer this question yet. In further research, it has to be determined when skin is ready for the next load without the risk of potential skin damage, maybe even calculating and representing a cooling curve for hands might be possible.

The values for the thumb are correct for this angle of measurement, but since the main contact with apparatus is on the inner side of the thumb, measuring separately and from a different angle would give different temperatures. To get more precise data, the thumb should be measured from a different angle.

When we observe low temperature differences (in the order of a tenth of a degree Celsius), it is not enough to rely on any non-contact temperature device because low-cost radiation thermometers and thermal imagers are not capable of accurate or consistent measurement of temperature differences. Therefore, the use of an accurate (calibrated) non-contact temperature device is necessary.

Author Contributions: Conceptualization, investigation and methodology: K.Š., I.Č., M.P. and I.P.; measurements: K.Š., I.P.; research validation, analysis I.Č.; data curation, writing-original draft preparation, visualization: K.Š.; review, editing and supervision: K.Š., I.Č., M.P. and I.P. All authors have read and agreed to the published version of the manuscript.

Funding: The authors acknowledge the financial support from the Slovenian Research Agency (research core funding No. P2-0225 and P5-0147).

Institutional Review Board Statement: The study was conducted according to the guidelines of the Declaration of Helsinki and approved by the Ethical Commission of the University of Ljubljana's Faculty of Sport (13 September 2018; 12_2018).

Informed Consent Statement: Informed consent was obtained from all subjects involved in the study.

Data Availability Statement: The data presented in this study are available on request from the corresponding author.

Conflicts of Interest: The authors declare no conflict of interest. The funders had no role in the design of the study; in the collection, analyses, or interpretation of data; in the writing of the manuscript, or in the decision to publish the results.

\section{References}

1. Infrared \& Thermal Imaging Applications. Available online: https://www.techimaging.com/applications/infrared-thermalimaging-applications (accessed on 18 May 2021).

2. Glik, J.; Cholewka, A.; Stanek, A.; Sieroń, K.; Mikuś-Zagórska, K.; Knefel, G.; Nowak, M.; Kawecki, M.; Englisz, B. Thermal imaging and planimetry evaluation of the results of chronic wounds treatment with hyperbaric oxygen therapy. Adv. Clin. Exp. Med. 2019, 28, 229-236. [CrossRef] [PubMed]

3. Lahiri, B.; Bagavathiappan, S.; Jayakumar, T.; Philip, J. Medical applications of infrared thermography: A review. Infrared Phys. Technol. 2012, 55, 221-235. [CrossRef] [PubMed]

4. Hildebrandt, C.; Raschner, C.; Ammer, K. An Overview of Recent Application of Medical Infrared Thermography in Sports Medicine in Austria. Sensors 2010, 10, 4700-4715. [CrossRef] [PubMed]

5. Kasprzyk-Kucewicz, T.; Cholewka, A.; Bałamut, K.; Kownacki, P.; Kaszuba, N.; Kaszuba, M.; Stanek, A.; Sieroń, K.; Stransky, J.; Pasz, A.; et al. The applications of infrared thermography in surgical removal of retained teeth effects assessment. J. Therm. Anal. Calorim. 2021, 144, 139-144. [CrossRef]

6. Sousa, E.; Vardasca, R.; Teixeira, S.; Seixas, A.; Mendes, J.; Costa-Ferreira, A. A review on the application of medical infrared thermal imaging in hands. Infrared Phys. Technol. 2017, 85, 315-323. [CrossRef]

7. Gulyaev, Y.; Markov, A.; Koreneva, L.; Zakharov, P. Dynamical infrared thermography in humans. IEEE Eng. Med. Biol. Mag. 1995, 14, 766-771. [CrossRef]

8. Bouzida, N.; Bendada, A.; Maldague, X.P. Visualization of body thermoregulation by infrared imaging. J. Therm. Biol. 2009, 34, 120-126. [CrossRef]

9. Martínez-Nova, A.; Jiménez-Cano, V.; Caracuel-López, J.; Gómez-Martín, B.; Escamilla-Martínez, E.; Sánchez-Rodríguez, R. Effectiveness of a Central Discharge Element Sock for Plantar Temperature Reduction and Improving Comfort. Int. J. Environ. Res. Public Health 2021, 18, 6011. [CrossRef]

10. Kasprzyk, T.; Cholewka, A.; Kucewicz, M.; Sieroń, K.; Sillero-Quintana, M.; Morawiec, T.; Stanek, A. A quantitative thermal analysis of cyclists' thermo-active base layers. J. Therm. Anal. Calorim. 2018, 136, 1689-1699. [CrossRef] 
11. Kasprzyk-Kucewicz, T.; Szurko, A.; Stanek, A.; Sieroń, K.; Morawiec, T.; Cholewka, A. Usefulness in Developing an Optimal Training Program and Distinguishing between Performance Levels of the Athlete's Body by Using of Thermal Imaging. Int. J. Environ. Res. Public Health 2020, 17, 5698. [CrossRef]

12. Napier, J.R. The prehensile movements of the human hand. Pathol. Basic Sci. 1956, 38, 902-913. [CrossRef]

13. Aarkaev, L.; Suchilin, N. How to Create Champions: The Theory and Methodology of Training Top-Class Gymnasts; Meyer \& Meyer Fachverlag und Buchhandel GmbH: Aachen, Germany, 2004.

14. Pušnik, I.; Čuk, I.; Hadžič, V. Influence of new Anatomic Ring Design on Palm Skin Temperature. Sci. Gymnast. J. 2017, 9, 61-70.

15. Zhang, M.; Roberts, V. The effect of shear forces externally applied to skin surface on underlying tissues. J. Biomed. Eng. 1993, 15, 451-456. [CrossRef]

16. Zhang, M.; Turner-Smith, A.R.; Roberts, V.C. The Reaction of Skin and Soft Tissue to Shear Forces Applied Externally to the Skin Surface. Proc. Inst. Mech. Eng. Part H J. Eng. Med. 1994, 208, 217-222. [CrossRef]

17. Sangiorgi, S.; Manelli, A.; Congiu, T.; Bini, A.; Pilato, G.; Reguzzoni, M.; Raspanti, M. Microvascularization of the human digit as studied by corrosion casting. J. Anat. 2004, 204, 123-131. [CrossRef]

18. Zhang, M.; Mak, A.F.T. In vivo friction properties of human skin. Prosthet. Orthot. Int. 1999. Available online: http://www. oandplibrary.org/poi/1999_02_135.asp (accessed on 18 May 2021).

19. Sulzberger, M.B.; Cortese, T.A.; Fishman, L.; Wiley, H.S.; Peyakovich, P.S. Studies on Blisters Produced by Friction. J. Investig. Dermatol. 1966, 47, 456-465. [CrossRef]

20. Hall, J.E.; Guyton, A.C. Guyton and Hall Textbook of Medical Physiology, 13th ed.; Elsevier: Amsterdam, The Netherlands, 2016; p. 912.

21. Zontak, A.; Sideman, S.; Verbitsky, O.; Beyar, R. Dynamic Thermography: Analysis of Hand Temperature During Exercise. Ann. Biomed. Eng. 1998, 26, 988-993. [CrossRef]

22. Kwon, Y.S.; Robergs, R.A.; Kravitz, L.R.; Gurney, B.A.; Mermier, C.M.; Schneider, S.M. Palm Cooling Delays Fatigue during High-Intensity Bench Press Exercise. Med. Sci. Sports Exerc. 2010, 42, 1557-1565. [CrossRef]

23. Bennett, S.L.; Goubran, R.; Knoefel, F. Measurements of change in thermal images due to applied pressure. In Proceedings of the 2015 IEEE International Symposium on Medical Measurements and Applications (MeMeA 2015), Torino, Italy, 7-9 May 2015; pp. 30-35. [CrossRef]

24. Pušnik, I.; Čuk, I. Thermal Imaging of Hands during Simple Gymnastics Elements on the Wooden Bar with and without the use of Magnesium Carbonate. Sci. Gymnast. J. 2014, 6, 67-72.

25. Anbar, M. Quantitative Dynamic Telethermometry in Medical Diagnosis and Management; CRC Press: Boca Raton, FL, USA, 1994.

26. Mercer, J.B.; De Weerd, L. Thermography and thermal symmetry. In Proceedings of the IEEE International Symposium on Medical Measurements and Applications (MeMeA 2014), Lisbon, Portugal, 11-12 June 2014; pp. 4-6. [CrossRef]

27. Čuk, I.; Marinsek, M. Landing quality in artistic gymnastics is related to landing symmetry. Biol. Sport 2013, 30, 29-33. [CrossRef]

28. Pajek, M.B.; Hedbávný, P.; Kalichová, M.; Čuk, I. The asymmetry of lower limb load in balance beam routines. Sci. Gymnast. J. 2016, 8, 5-13.

29. Sundqvist, K.L. Evaluation of Hand Skin Temperature-Infrared Thermography in Combination with Cold Stress Tests Health Science. Ph.D. Thesis, Luleå University of Technology, Luleå, Sweden, 2017.

30. Fernández-Cuevas, I.; Marins, J.C.B.; Lastras, J.A.; Carmona, P.M.G.; Cano, S.P.; García-Concepción, M.Á.; Sillero-Quintana, M. Classification of factors influencing the use of infrared thermography in humans: A review. Infrared Phys. Technol. 2015, 71, 28-55. [CrossRef]

31. Perić, D.; Livada, B.; Perić, M.; Vujić, S. Thermal Imager Range: Predictions, Expectations, and Reality. Sensors 2019, 19 , 3313. [CrossRef]

32. Pušnik, I.; Geršak, G. Evaluation of the Size-of-Source Effect in Thermal Imaging Cameras. Sensors 2021, 21, 607. [CrossRef]

33. Chudecka, M.; Lubkowska, A. Thermal maps of young women and men. Infrared Phys. Technol. 2015, 69, 81-87. [CrossRef]

34. Pauk, J.; Wasilewska, A.; Ihnatouski, M. Infrared Thermography Sensor for Disease Activity Detection in Rheumatoid Arthritis Patients. Sensors 2019, 19, 3444. [CrossRef]

35. Power-Cylindrical Grip-Functional Anatomy of the Hand. 2016. Available online: https://functionalanatomyofthehand. wordpress.com/2016/04/14/anatomy-of-the-hand-3 (accessed on 20 May 2021).

36. Dowdell, T. Is Gymnastics a dangerous sport in the Australian club context? Sci. Gymnast. J. 2011, 3, $13-25$.

37. Sands, W.; McNeal, J.; Jemni, M.; Penitente, G. Thinking Sensibly About Injury Prevention and Safety. Sci. Gymnast. J. 2011, 3 , 43-58.

38. Malovrh, M. Non-invasive evaluation of vessels by duplex sonography prior to construction of arteriovenous fistulas for haemodialysis. Nephrol. Dial. Transplant 1998, 13, 125-129. [CrossRef] 